SMoking has either a beneficial or harmful effect on the course and recurrence of ulcerative colitis and Crohn's disease respectively. Transdermal application of nicotine had similar effects in ulcerative colitis and therefore was considered to be an effective basic drug which could be further developed in the search for new compounds in the treatment of acute exacerbations of corticosteroid resistant ulcerative colitis. In this communication the short-term use of nicotine in ulcerative colitis is reviewed.

Key words: nicotine, smoking, Crohnn's disease, ulce rative colitis, cytokines

\section{Smoking and nicotine in inflammatory bowel disease: good or bad for cytokines?}

\section{F. J. Zijlstra}

Department of Pharmacology, Faculty of Medicine and Health Sciences, Erasmus University Rotterdam, PO Box 1738, 3000 DR Rotterdam, The Netherlands

Tel: $(+31) 104087550$

Fax: (+31) 104366839

Email: zijlstra@farma.fgg.eur.nl

\section{Introduction}

\section{Epidemiology}

Although ulcerative colitis (UC) and Crohn's disease (CD) are both indicated as inflammatory bowel diseases (IBD) with similar clinical aspects, there are contrasting features, like the adverse effects of smoking on the clinical course of these diseases. In UC evidence was found that the occurrence of relapses was increased in ex-smokers shortly after cessation. ${ }^{1}$ Smoking also has some protective effects against disorders in which the immunological system is in inbalance, such as Parkinson's disease, ${ }^{2}$ Alzheimer's disease ${ }^{3}$ and primary sclerosing cholangitis (PSC) $^{4}$ (Table 1). Approximately $70 \%$ of patients suffering from PSC have associated IBD, most UC, whereas coversely, $5 \%$ of UC patients have associated PSC. In contrast with these observations, smoking seems to have a harmful effect on the course of CD. ${ }^{5}$

The mechanism underlying the beneficial effects of nicotine in UC is still unknown.

\section{Pharmacology}

Smoking cigarettes results in a fast absorption of nicotine and subsequent distribution over all tissues, followed by accumulation and simultaneously started degradation ( $\mathrm{T}_{1 / 2}$ approx. $2 \mathrm{~h}$ ). Smoking one cigarette yields the mean uptake of $1 \mathrm{mg}$ of nicotine. ${ }^{6}$ Nicotine binds to acetylcholine receptors located both in the central nervous system and the peripheral nervous system. Presynaptic stimulation results in the release of neurotransmittors and local hormones, which in turn attributes to either suppression or not of the immune system.

\section{Immunology}

Nicotine has an inhibitory effect on eicosanoid production. The in vitro synthesis of thromboxane $\mathrm{A}_{2}$ by human leukocytes is decreased ${ }^{8}$ and overall synthesis of eicosanoids by rectal mucosae from nicotine-treated rabbits was dose-dependently

Table 1. Main effects of nicotine

Effect Reference

Diseases

Parkinson's disease

Alzheimer disease

Primary sclerosing cholangitis

Ulcerative colitis

Crohn's disease

$\begin{array}{ll}\downarrow & 2 \\ \Psi & 3 \\ ¥ & 4 \\ & 1,19 \\ 5,25\end{array}$

Pharmacology/physiology

Presynaptic transmitter release

Vasoconstriction

Rectal blood flow

Gastric secretion, motility

Permeability

$\begin{array}{ll}\uparrow & 7 \\ \searrow & 7 \\ & 12 \\ 13 \\ 14\end{array}$

Immunology

Eicosanoid synthesis

Cytokine synthesis

Apoptosis 
inhibited. ' Furthermore eicosanoid content was decreased in bronchoalveolar lavage fluids from smokers in comparison with those obtained from healthy non-smokers. ${ }^{10}$

As eicosanoids are considered to be mainly secondary mediators of inflammation, they will only modulate the course of the inflammation initiated by other bio-active pro-inflammatory mediators, such as the cytokines tumour necrosis factor $\alpha$ (TNF $\alpha$ ) or interleukin-1 $\beta$ (IL-1 $\beta$ ). In an animal model for subacute colitis we observed this time related release of mediators and the beneficial effect of nicotine on the synthesis of pro-inflammatory cytokines. ${ }^{11}$

\section{Physiological effects}

Stimulation of peripheral nicotinic receptors leads to increased catecholamines and noradrenaline, resulting in vasoconstriction, tachycardia and an increased myocardial contraction. After smoking rectal blood flow in UC was diminished, ${ }^{12}$ whereas both gastric acid secretion and motility are enhanced in man. ${ }^{13}$ It also has been suggested that nicotine tightens the gut, which consequently leads to a diminished permeability and less availability of mediators of inflammation, ${ }^{14}$ although increased permeability mainly is found in the ileum, more or less resembling Crohn's disease. The diminished availability of inflammatory mediators therefore could be the result of local changes in blood flow and subsequent disturbed distribution in the gastrointestinal tract.

The immunoregulatory role of peripheral lymphocytes migrating into inflamed colonic mucosa is evident. Lymphocytes do have nicotinic receptors with a high affinity for nicotine, ${ }^{15}$ which cannot be replaced by common muscarinic or nicotinic receptor antagonists. ${ }^{16}$

\section{The Use of Nicotine in Colitis}

\section{Experimental models}

Studies on the effects of smoke describe short-term and long-term exposure to tobacco smoke, in which formation of pro-inflammatory mediators by alveolar macrophages has been investigated. ${ }^{17}$ Besides that a markedly diminished formation of cytokines by peritoneal macrophages was found, implicating systemic effects of nicotine on suppression of the immune system. That is in agreement with our findings in mice, where both IL-1 $\beta$ and TNF $\alpha$ synthesis by colonic mucosa were almost completely inhibited after nicotine treatment. ${ }^{11}$

Diminished mucosal levels of pro-inflammatory cytokines not always leads to an improvement of the (sub)acute ulcerative colitis. ${ }^{18}$ The complex cascade of mediators formed during the initial event and the sub-acute and chronic phases-such as cytokines, lipid mediators, platelet activating factor, nitric oxide, neuropeptides and local hormones as angiotensin, histamine, serotonin and substance P-leads to interactions and feed-back mechanisms which still have to be evaluated.

\section{Clinical effects of nicotine}

Transdermal nicotine for active UC during 6 weeks has been proven to be effective as additional treatment regimen besides the low-dose continuation of corticosteroids and/or 5-amino-salicylic acid (5-ASA). ${ }^{19}$ Cinical observations following diary instructions revealed a significant decreased disease activity score (DAS), including daily stool frequency, blood loss, stool consistency, abdominal pain, fecal urgency and overall clinical grade. In the placebo group how ever, also (less) significant DAS values were found for almost all items. Histology, mainly based on the number of neutrophils, was only significant in the nicotine-treated group (mean 2.6 at baseline to 1.7 after 6 weeks, scale $0-4, P<0.001)$. The attributive effect of nicotine to maintenance therapy of corticoste roids ( $<10 \mathrm{mg}$ daily) or mesalasine (5-ASA) could be due to a further suppression of cytokine synthesis.

In this study 28 of 35 patients receiving nicotine patches were treated with mesalasine, whereas the other seven patients received glucocorticosteroids.

We have shown that daily intake of $4 \mathrm{~g}$ mesalasine only partly suppressed cytokine synthesis by peripheral lymphocytes. ${ }^{20}$ Therefore nicotine only can be considered as an additive therapy and not a replacement therapy for corticosteroid resistant ulcerative colitis. Transdermal nicotine mainly inhibits in vitro stimulated IL-2 production by human peripheral mononuclear cells. Only small effects on synthesis of TNF $\alpha$, IFN-gamma and IL-10 were observed. ${ }^{20,21}$

\section{In vitro effects of nicotine on cytokine synthesis}

After incubation with prednisolone cytokine synthesis by human peripheral mononuclear cells was completely inhibited $\left(10^{-5} \mathrm{M}\right)$. At comparable doses nicotine only diminished the IL-2 and TNF $\alpha$ production by $40-50 \%{ }^{22}$ A $35 \%$ decrease of this production was already achieved at concentrations of $5.10^{-9} \mathrm{Mof}$ nicotine, comparable with a mean intake of 10-15 cigarettes a day. Surprisingly this inhibitory effect of nicotine could not be reversed by a number of agonists and antagonists, such as carbachol (AchMreceptor agonist), atropine (Ach-Mreceptor antagonist), hexamethonium and pancuronium (nicotinic receptor antagonists), prednisolone and dexamethasone (corticosteroids) or isoprenaline and salbutamol ( $\beta$-adrenoceptor agonists). ${ }^{16}$ From these observations we concluded that a noncholinergic receptor is involved or that an irreversible antagonism of the second messenger system takes place. 


\section{Concluding Remarks}

The idea that a certain differentiation occurs in subpopulations of lymphocytes after migration into the mucosal tissue, either inflamed or non-inflamed, lead to the classification of Th1 cell related Crohn's disease and Th2 cell related ulcerative colitis. A disbalance in pro- and anti-inflammatory cytokines could subsequently result in CD or UC. From this concept the beneficial effect of nicotine in UC and on the other hand the harmful activity after smoking in $\mathrm{CD}$ could not be clarified. New concepts have been supposed to unravel mechanisms of IBD. Not only CD4+ cells, but also mast cells and macrophages are important donors of triggers in the cell-cell interaction which takes place in the lumen. Stimulation of $\mathrm{CD} 4+$ cells by IL-12 will predominantly lead to synthesis of IFN-gamma and IL-2 from Th1 cells, IL 4 and IL-10 from Th 2 cells and TGF $\beta$ from Th 3 cells. ${ }^{23} \mathrm{~A}$ main part of these stimulated $\mathrm{CD} 4+$ cells will disappear from the inflamed region by apoptosis. Neutrophil survival was prolonged after incubation with nicotine. ${ }^{24}$ This could be due to a diminished release of IL-12 from activated macrophages. Therefore the exclusive role of IL-12 in this interplay should be made clear before we could conclude that smoking and nicotine in IBD is good or bad, ${ }^{25}$ based on cytokine patterns as prominent markers for mediators of inflammation.

\section{References}

1. Calkins BM. A meta-analysis of the role of smoking in inflammatory bowel disease. Dig Dis Sci 1989; 34: 1841-1854.

2. Morens DM, Grandinette A, Reed D, White LR, Ross GW. Cigarette smoking and protection from Parkinson's disease. Neurology 1995; 45: 1041-1051.

3. Van Duijn CM, Hofman A. Relation between nicotine intake and Alzheimer disease. Br Med J 1991; 302: 1491-1494.

4. Loftus E, Sandborn W, Tremaine W, Mahoney D, Zinsmeister A, Offord K, Melton L Primary scle rosing cholangitis is associated with non-smoking: a case control study. Gastroenterology 1996; 110: 1503-1506.

5. Cottone M, Rosselli M, Orlando A, Oliva L, Puleo A, Cappello M, Trania M, Tonelli F, Pagliaro L. Smoking habits and recurrence in Crohn's disease. Gastroenterology 1994; 106: 643-648.

6. Benowitz NL, Jacob P. Daily intake of nicotine during cigarette smoking. Clin Pharmacol Ther 1984; 35: 499-504.

7. Hersey P, Prendergast D, Edwards A. Effects of cigarette smoking on the immunesystem. Med J Aust 1983; 2: 425-429.
8. Saareks V, Riutta A, Mucha I, Alanko J, Vapaatalo H. Nicotine and cotinine modulate eicosanoid production in human leukocytes and platelet rich plasma. Eur J Pharmacol 1993; 248: 345-349.

9. Zijlstra FJ, Scrivastava ED, Rhodes M, van Dijk APM, Fogg F Samson HJ, Copeman M, Russell MAH, Feyerabend C, Williams GT, Pullan RD, Thomas GAO, van Blankenstein M, Wilson JHP, Allen A, Rhodes J. Effect of nicotine on rectal mucus and mucosal eicosanoids. Gut 1994; 35: $247-251$

10. Zijlstra FJ, Vincent JE, Mol WM, Hoogsteden HC, van Hal PTW, Jongejan RC. Eicosanoid levels in broncho alveolar lavage fluid of young female smokers and non-smokers. Eur J Pharmacol 1992; 22: 301-306.

11. Van Dijk APM, Madretsma GS, Keuskamp ZJ, Zijlstra FJ. Nicotine inhibits cytokine production by mouse colonic mucosa. Eur J Pharmacol 1995; 278: R11-R12.

12. Scrivastava ED, Russell MAH, Feyerabend C, Rhodes J. Effect of ulcerative colitis and smoking on rectal blood flow. Gut 1991; 31: 1021-1024.

13. Endoh K, Leung FW. Effects of smoking and nicotine on the gastric mucosa: a review of clinical and experimental evidence. Gastroentero logy 1994; 107: 864-878.

14. Soderholm J, Olaison G, Sjodahl R, Tahesson C. Smoking and intestinal absorption of ora polyethyleneglycols in Crohn's disease. Scand J Gastroenterol 1993; 28: 163-167.

15. Grabczewska E, Lakowska-Bozek H, Malinski W, Ryzewski J. Cholinergic muscarinic and nicotinic binding by human lymphocytes: differences between peripheral blood cells and cultivated cell lines. Int J Tissue React 1990; 12: 281-289.

16. Madretsma GS, van Dijk APM, Tak CJAM, Wilson JHP, Zijlstra FJ. Nicotine induced inhibition of IL-2 and TNF $\alpha$ production by human mononuclear cells is mediated via a non-cholinergic receptor. Im munopharmacology 1998; in press.

17. Pessina GP, Paulesu L, Corradeshi F, Luzzi E, Tanzini C, Aldinucci A, Di Stefano A, Bocci V. Chronic cigarette smoking enhances spontaneous release of tumor necrosis factor $\alpha$ from alveolar macrophages of rats. Mediators Inflamm 1993; 2: 423-428.

18. Van Bergeijk JD, van Meeteren ME, Tak CJAM, van Dijk APM, Meijssen MAC, Wilson JHP, Zijlstra FJ. Somatostatin does not attenuate intestinal injury in dextran sodium sulphate-induced subacute colits. Mediators Inflam $m$ 1998;

19. Pullan RD, Rhodes J, Ganesh S, Mani V, Morris JS, Williams GT, Newcombe RG, Russell MAH, Feyerabend C, Thomas GAO, Sawe U. Transdermal nicotine for active ulcerative colitis. New Engl J Med 1994; 330: 811-815.

20. Van Dijk APM, Meijssen MAC, Brouwer AJBW, Hop WCJ, van Bergeijk JD, Feyerabend C, Wilson JHP, Zijlstra FJ. Transdermal nicotine inhibits PHAstimulated interleukin-2 production by human peripheral mononuclear cells. Eur J Clin Invest; In press.

21. Madretsma GS, Wolters L, van Dijk APM, Tak CJAM, Feye rabend C, Wilson JHP, Zijlstra FJ. In vivo effect of nicotine on cytokine production by human non-adherent mononuclear cells. Eur J Gastroenterol Hepatol 1996; 8: 1017-1020.

22. Madretsma GS, Donze GJ, van Dijk APM, Tak CJAM, Wilson JHP, Zijlstra FJ Nicotine inhibits the in vitro production of interleukin 2 and tumor necrosis factor $\alpha$ by human mononuclear cells. Im munopharmacology 1996; 35: 47-51.

23. Proceedings Falk Symposium No 104, Induction and Modulation of Gastrointestinal Inflammation, Saarbrücken, 1998.

24. Aoshiba K, Nagai A, Yasui S, Konno K. Nicotine prolongs neutrophil survival by suppressing apoptosis. J Lab Clin Med 1996; 127: 186-194.

25. Rhodes J, Thomas GOA. Smoking: good or bad for inflammatory bowel disease? Gastroenterology 1994; 106: 807-810.

\section{Received and accepted 12 March 1998}




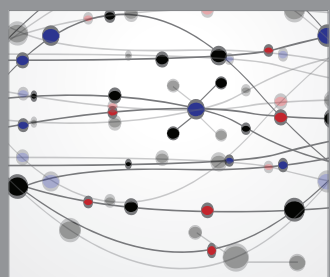

The Scientific World Journal
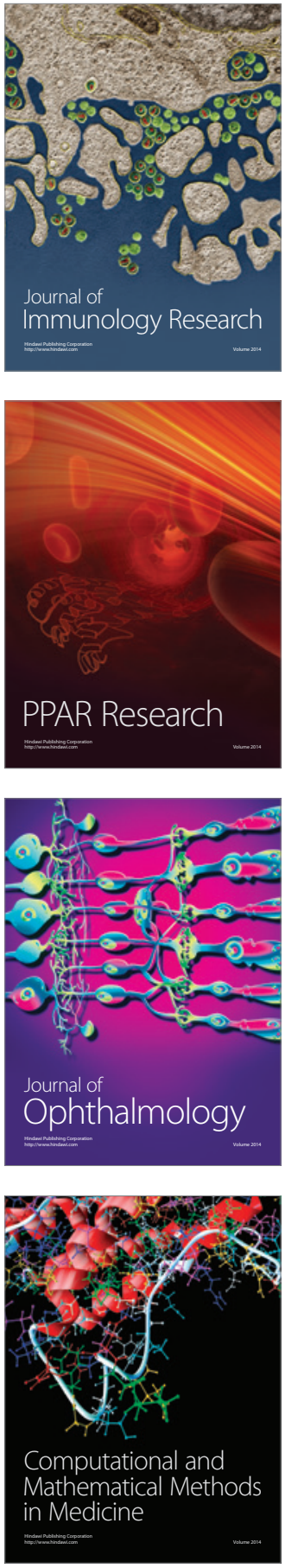

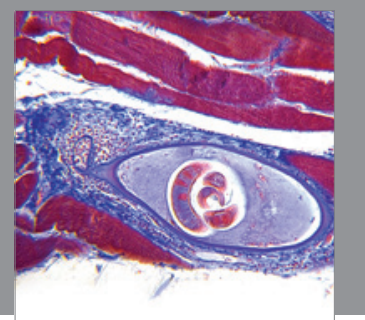

Gastroenterology

Research and Practice
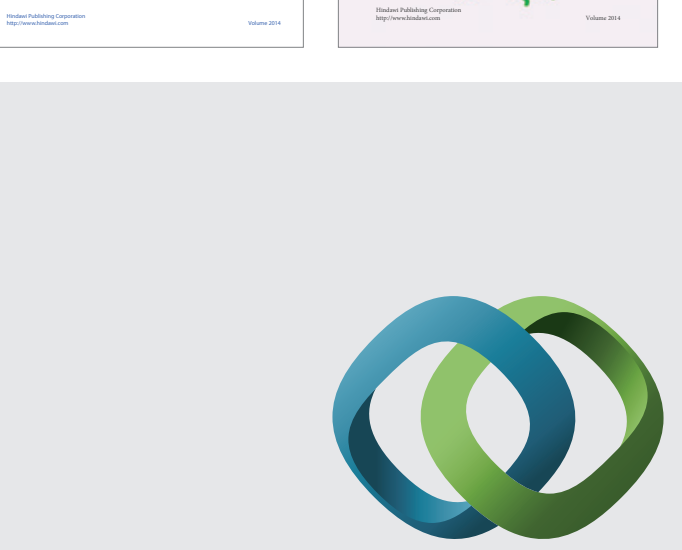

\section{Hindawi}

Submit your manuscripts at

http://www.hindawi.com
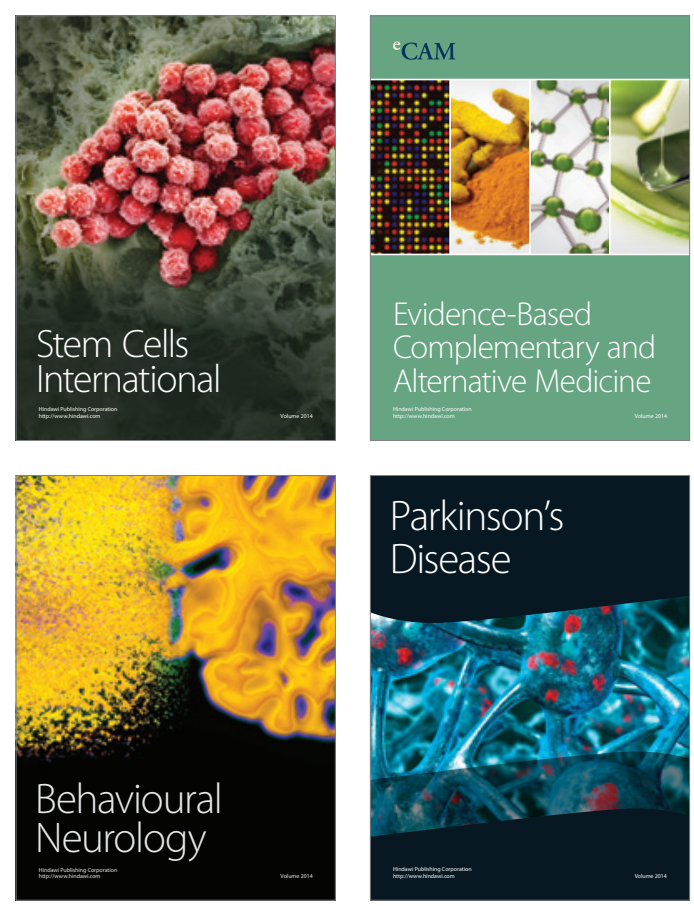

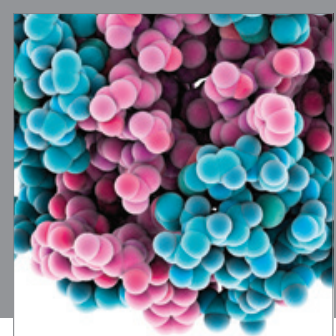

Journal of
Diabetes Research

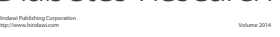

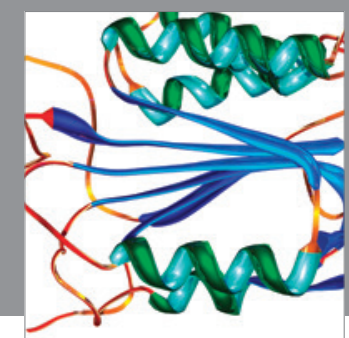

Disease Markers
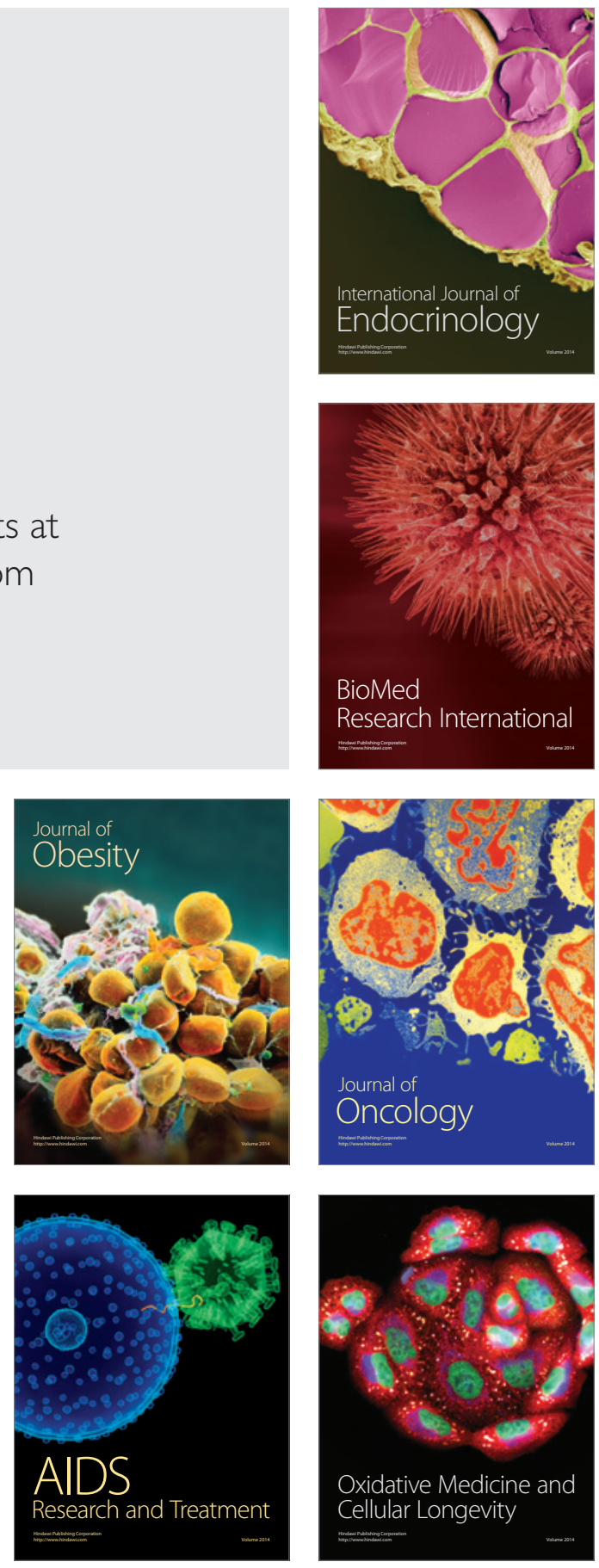